\title{
Células-tronco mononucleares associadas ao plasma rico em plaquetas na consolidação de falha óssea no cão. Estudo piloto
}

\author{
[Mononuclear stem cells associated with platelet-rich plasma in the consolidation of \\ bone defects in dogs. A pilot study]
}

\author{
A.L.T. Barbosa ${ }^{1}$, J.E.W. Schossler ${ }^{2}$, A.G. Raiser ${ }^{2}$, G.M.C. Serafini ${ }^{2}$, T.L.E. Treichel ${ }^{2}$, R.N. Libardoni ${ }^{3}$, F. \\ Marconato $^{2}$, M.C. Silveira ${ }^{3,4}$, D.L. Graça ${ }^{2}$, D.B. Martins ${ }^{2}$, R.M. Zanetti ${ }^{3,5}$, S.T.A. Lopes ${ }^{2}$ \\ ${ }^{1}$ Aluno de pós-graduação - Universidade Federal de Santa Maria - UFSM - Santa Maria, RS \\ ${ }^{2}$ Universidade Federal de Santa Maria - UFSM - Santa Maria, RS \\ ${ }^{3}$ Aluno de graduação - Universidade Federal de Santa Maria - UFSM - Santa Maria, RS \\ ${ }^{4}$ Bolsista de iniciação científica do PIBIC - UFSM - Santa Maria, RS \\ ${ }^{5}$ Bolsista de iniciação científica do CNPq - UFSM - Santa Maria, RS
}

\begin{abstract}
RESUMO
A padronização de técnicas e o teste da associação do Plasma Rico em Plaquetas (PRP) e das CélulasTronco Mononucleares (CTMs) na consolidação de falhas ósseas corticais, por meio de avaliação clínica, biomecânica, radiológica e histológica, é avaliada em um estudo piloto. Foram utilizados seis cães adultos, fêmeas, sem raça definida, pesando entre 5 e $10 \mathrm{~kg}$, separados por sorteio aleatório em seis tratamentos. Foi confeccionada uma falha elíptica de 1,0x0,4cm na cortical medial diafisária da tíbia direita de cada animal, sendo preenchida de acordo com o tratamento proposto. No cão I, a falha foi preenchida com solução fisiológica (SF); no II, com o PRP; no III, com a fração total das células mononucleares (FTCM); no IV, com a fração vascular estromal (FVE); no V, com o PRP associado à FTCM; no VI, com a associação PRP e FVE. Foram realizadas avaliações: clínicas, diariamente; dos graus de claudicação, semanalmente; radiológica e perimetria da coxa, antes, no pós-operatório imediato, aos 7, 14, 21 e 30 dias; biomecânica, antes do procedimento, aos 10, 20 e 30 dias; e biópsias, aos 15 e 30 dias. A FTCM obteve uma contagem e viabilidade média de 2,0x10 ${ }^{8}$ cél. e $90 \%$, respectivamente, enquanto a FVE obteve $3 \times 10^{6}$ cél. e $50 \%$. O PRP concentrou, em média, sete vezes o número inicial de plaquetas do sangue total, de $250.000 \mathrm{\mu l}^{-1}$ plaquetas no sangue total para $1.750 .000 \mathrm{\mu l}^{-1}$ plaquetas no PRP. Obteve-se padronização adequada de técnicas, possibilitando o teste da associação entre as células-tronco mononucleares (CTMs) e o plasma rico em plaquetas (PRP), assim como seu uso isolado, no reparo de falhas ósseas corticais, indicando a possibilidade de a associação FTCM e PRP ser o melhor tratamento.
\end{abstract}

Palavras-chave: fatores de crescimento, gel de plaquetas, fração total de CTM, osteogênese

\begin{abstract}
The standardization of techniques and tests of the association of Platelet Rich Plasma (PRP) and Mononuclear Stem Cells (MSCs) in the consolidation of cortical bone defects by clinical, biomechanical, radiological, and histological analysis is evaluated in a pilot study. Six adult female dogs of mixed breed, weighing between 5 and $10 \mathrm{~kg}$, separated by random draw in six treatments were used. An elliptical failure of $1.0 \times 0.4 \mathrm{~cm}$ was done in the medial diaphyseal cortical of the right tibia of each animal, that was filled according with the proposed treatment. In dog I, the failure was filled with saline (S), in dog II with PRP, in dog III with total mononuclear cell fraction (TMCF), in dog IV with stromal vascular fraction (SVF), in dog V with association of PRP and TMCF, and in dog VI with an association of PRP and SVF. Daily clinical evaluation, weekly degrees of lameness, radiological and girth before, immediate postoperative, 7, 14, 21 and 30 days, biomechanics before the procedure, at 10, 20 and 30 days, and biopsies at 15 and 30 days were performed. The TMCF got a count and viability of 2,0x10 ${ }^{8}$ cells and $90 \%$ respectively, while for SVF it was $3 \times 10^{6}$ cells and 50\%, respectively. The PRP concentrated on average
\end{abstract}

Recebido em 31 de outubro de 2012

Aceito em 11 de fevereiro de 2014

E-mail: rafaele.alcantara@agricultura.gov.br 
seven times the original number of platelets from whole blood, platelets from whole blood $250.000 \mu l^{-1}$ to 1.750.000 $\mu l^{-1}$ platelets in PRP. This afforded adequate standardization of techniques, enabling the test of association between mononuclear stem cells (MSCs) and platelet-rich plasma(PRP), as well as their separate use to repair cortical bone defects, indicating the possibility of the association between FTCM and PRP to be the best treatment.

Keywords: growth factors, platelet gel, total stem cells fraction, osteogenesis

\section{INTRODUÇÃO}

Uma fonte autógena e barata de fatores de crescimento, o plasma rico em plaquetas (PRP) é preparado a partir de pequena quantidade de sangue total retirado do próprio paciente, no período pré-operatório. É também denominado concentrado de plaquetas (CP), plasma enriquecido com plaquetas, gel de plaquetas e plasma rico em fatores de crescimento (Lieberman et al., 2002).

A concentração dos fatores de crescimento (FCs) no gel de plaquetas é significativamente alta, resultando em 10 a 25 vezes mais PDGF e TGF$\beta$ do que em um processo êstiocog sem adição de PRP. Sua aplicação clínica tem potencial para aumentar a cicatrização do tecido ósseo e a osteogênese (Floryan e Berghoff, 2004).

Há uma tendência atual do uso da engenharia tecidual na reposição de tecidos ou órgãos danificados, sendo o transplante celular uma das estratégias utilizadas para esse fim. Nesse método, o veículo não só transporta as células, mas serve de guia para o crescimento do novo tecido (Kaigler e Mooney, 2001).

Para que as CT se diferenciem em tecido ósseo, elas precisam de um osteocondutor, um carreador que forneça à célula uma estrutura e características de superfície apropriadas à adesão e proliferação celular. Esse material deve possuir porosidade para permitir a proliferação celular e desenvolvimento da rede vascular (Bucholz, 2002).

O PRP também foi demonstrado como uma possível alternativa promissora, mais eficiente que o enxerto, já que reúne os FCs liberados pelas plaquetas, acelerando processos reparadores em muitas áreas. Na odontologia, estudos comprovaram sua eficácia em promover uma osteogênese mais rápida, com melhor qualidade do trabeculado no reparo do osso alveolar (Brandão, 2005).
Este estudo piloto teve por objetivo a padronização de técnicas e teste da associação do PRP e das Células-Tronco Mononucleares (CTMs) na consolidação de falhas ósseas corticais, comparando, por meio de avaliação clínica, biomecânica, radiológica e histológica, a resposta reparadora ao uso das frações das CTMs e PRP isolados, e das frações das CTMs associadas ao PRP a ser utilizado em pesquisa subsequente. Dessa forma, visa oferecer uma alternativa para reduzir o tempo de reabilitação do paciente ortopédico por meio de uma formação óssea mais rápida e de melhor qualidade, especialmente em perdas ósseas.

\section{MATERIAL E MÉTODOS}

Foram utilizados seis cães adultos, fêmeas, sem raça definida, pesando entre 5 e 10kg, provenientes do Biotério Central da Universidade Federal de Santa Maria (UFSM). Após a escolha dos animais, estes passaram por uma avaliação clínica e laboratorial, sendo considerados sadios. Todo o experimento foi conduzido conforme normas do Colégio Brasileiro de Experimentação Animal (COBEA) e com aprovação do Comitê de Ética da UFSM sob o parecer de aprovação número 57/2009.

Os animais foram separados por sorteio aleatório para seis tratamentos. Confeccionou-se uma falha elíptica de $1,0 \times 0,4 \mathrm{~cm}$ na cortical medial diafisária da tíbia direita de cada animal, sendo preenchida de acordo com o grupo ao qual o animal pertencia. No cão I, preencheu-se com solução fisiológica (SF); no II, com o plasma rico em plaquetas (PRP); no III, com a fração total das células mononucleares (FTCM); no IV, com a fração vascular estromal (FVE); no V, com o PRP associado à FTCM; no VI, com a associação PRP e FVE. Nos cães I, III e IV, foi utilizado Gelfoam ${ }^{\circledR}$ (esponja de gelatina absorvível estéril) como carreador.

Os animais foram preparados para a cirurgia com jejum sólido de 12 horas, líquido de 6 h e banho 
24 horas antes do procedimento. O protocolo anestésico constou de medicação pré-anestésica (MPA) com maleato de acepromazina $(0,05 \mathrm{mg}$

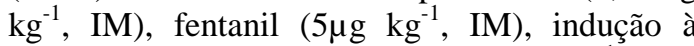
anestesia geral com propofol $\left(4,0 \mathrm{mg} \mathrm{kg}^{-1}, \mathrm{IV}\right)$, anestesia epidural com morfina $\left(0,1 \mathrm{mg} \mathrm{kg}^{-1}\right)$, bupivacaína 0,5\% e lidocaína 2,0\% (1ml $\left.4 \mathrm{~kg}^{-1}\right)$, ambas com vasoconstritor, e a manutenção com isoflurano, vaporizado em gás oxigênio a 100\% em circuito aberto (baraka), não reinalante, por ventilação espontânea.

Realizou-se a tricotomia ampla das regiões de acordo com o tipo de material a ser coletado para a punção de medula óssea: úmero bilateral e fossa trocantérica do fêmur bilateral (cães III e V); para coleta de tecido adiposo: região inguinal (grupos IV e VI); coleta de sangue jugular: pescoço (cães II, V e VI); e para acesso cirúrgico à tíbia direita em todos os animais. Trinta minutos antes da cirurgia foi administrado antibiótico profilático (cefalotina sódica, 30mg $\mathrm{kg}^{-1}, \mathrm{IV}$ ) em todos os animais. A antissepsia do local foi realizada com álcool-iodo-álcool. O decúbito foi lateral para as coletas de MO e ventrodorsal para as coletas de gordura e intervenção cirúrgica.

Foi realizada contagem plaquetária dos animais II, V e VI, permitindo obtenção de um padrão de sangue total inicial, que foi comparado com a contagem após o protocolo laboratorial de confecção do PRP.

Para a extração e isolamento da fração total de células mononucleares (FTCM) da medula óssea (MO), os animais já anestesiados foram colocados em decúbito lateral direito inicialmente, e esquerdo, na sequência, para a coleta de medula óssea. As amostras foram obtidas segundo a técnica de Olsson (2009), e processadas por meio da técnica descrita por Boyum (1968). O processamento do PRP foi realizado segundo a técnica descrita por Barbosa et al. (2008) modificada, com a proporção sangue/anticoagulante de 3:1 na coleta, PRP/trombina de 1:1 na obtenção do gel, usando 189G por 10min na primeira centrifugação, e 448G durante $5 \mathrm{~min}$ na segunda. A extração e processamento do tecido adiposo foram realizados conforme técnica descrita por Treichel et al. (2011).
Cada um dos cães foi submetido à terapia antiinflamatória de meloxicam $\left(0,1 \mathrm{mg} \mathrm{kg}^{-1}\right.$ de peso corporal, SC, SID, por quatro dias) e cloridrato de tramadol (4mg kg-1, SC, BID, por três dias), e curativos, diários ou a cada 48 horas, das feridas de pele, com solução fisiológica $\mathrm{NaCl}$ 0,9\%. Os pontos de pele dos animais foram retirados decorridos sete dias de pós-operatório. Os membros operados foram mantidos com bandagem de Robert Jones modificada durante sete dias, trocada a cada 48 horas para visualização dos pontos, ou sempre que fosse retirada. Os animais permaneceram em gaiolas individuais até o final das avaliações, aos 30 dias, com dois passeios individuais diários no solário, e um passeio diário externo sob guia.

Realizaram-se avaliações clínicas diárias, dos graus de claudicação, segundo classificação de Tudury e Raiser (1985), semanalmente, exames radiográficos e mensuração da perimetria da coxa no pós-operatório imediato, 7, 14, 21 e 30 dias. Foi realizada avaliação biomecânica na plataforma de força em padrão ortostático, segundo técnica descrita por Barbosa et al. (2011), antes do procedimento, aos 10, 20 e 30 dias para análise da transferência de peso.

As biópsias para avaliação histológica foram realizadas aos 15 e 30 dias, mediante anestesia geral e analgesia anteriormente descritas. Aos 15 dias durante a biópsia, retirava-se todo o tecido neoformado, refazendo-se a falha e aumentandoa para $1,5 \times 0,4 \mathrm{~cm}$ e realizando um novo tratamento. O material foi conservado em formol tamponado por 24h, passando, a seguir, ao processo de descalcificação por 30 dias, e após, incluído em blocos de parafina para posterior confecção das lâminas. Nos fragmentos provenientes da biópsia de 15 dias, não foi necessária a descalcificação.

Para o estudo histológico foram usados três métodos: Hematoxilina-eosina (HE), Von-Kossa (VK) e Vimentina (Vi). Os animais foram doados após o término das avaliações e completo restabelecimento, a partir de 15 dias da última biópsia.

\section{RESULTADOS E DISCUSSÃO}

Com relação às contagens e viabilidades, na fração total das células mononucleares (FTCM) obtiveram-se contagens médias de $2,0 \times 10^{8}$ cél. e 
viabilidade média de $90 \%$, dados condizentes com o adequado, já que Gengozian (2000) e Suter et al. (2004) indicam um transplante celular de um número igual ou maior a 2×106 cél. e viabilidade mínima de $90 \%$.

Segundo Treichel et al. (2011), a fração vascular estromal FVE, mesmo com uma quantidade total de células mononucleares e viabilidade menor que a da FTCM, oferece um melhor resultado, fato que Strem et al. (2005) creditam ao tecido adiposo conter dentro das células mononucleares de 100 a 1.000 vezes mais células pluripotentes em um $\mathrm{cm}^{3}$ do que a medula óssea. Neste estudo, obtiveram-se na FVE contagens de $3 \times 10^{6}$ cél. e viabilidade média de 50\%. Porém, apesar de a contagem estar dentro dos valores esperados, a viabilidade foi considerada baixa, sendo o protocolo modificado para torná-la adequada. No protocolo de Treichel et al. (2011) usava-se a associação da collagenase tipo I (Collagenase Type I C0130 ${ }^{\circledR}$, Sigma,-Aldrich, EUA) e tipo II (Collagenase Type II C6885 ${ }^{\circledR}$, Sigma-Aldrich, EUA) para a digestão do tecido adiposo. Observou-se uma melhora na viabilidade de FVE ao se substituir a associação desses dois tipos de collagenase apenas pela collagenase tipo II.

O protocolo de confecção do plasma rico em plaquetas (PRP) foi eficiente, concentrando aproximadamente sete vezes, a partir do sangue total. Os animais possuíam em média $250.000 \mathrm{\mu l}^{-}$ 1 plaquetas no sangue total, que, após o processamento do sangue, produziram um PRP com 1.750.000 $\mathrm{\mu l}^{-1}$ plaquetas em média. Esse resultado obtido foi superior ao indicado por Marx (2004) e Smith et al. (2006), que recomendam uma concentração de plaquetas viáveis de 3 a 5 vezes acima do que o encontrado no sangue total.

O estudo da produção óssea é mais facilmente avaliado em defeitos do que em modelos de fraturas com potencial para consolidação (Bouxsein et al., 2001). Por esse motivo, em nosso estudo optou-se pela realização de uma falha monocortical na diáfise média tibial. Dessa forma, foi possível acompanhar a consolidação óssea sem modificações advindas de um tratamento para manter a estabilidade da fratura; pois, estando uma das corticais íntegra, mantinha a estabilidade local. Com relação ao tamanho da falha, foi instituído o maior tamanho possível, que não gerasse fratura, compatível com o porte dos animais.

O grau de claudicação variou entre os animais conforme o comportamento individual, sendo os mais ativos os primeiros a chegarem ao grau $\mathrm{V}$. A intenção era utilizar a classificação de Tudury e Raiser (1985) para comparar a melhora entre os cães, comparando com as demais avaliações. Porém, aos cinco dias de pós-operatório, todos os animais já se encontravam nesse grau, mantendose assim nas demais avaliações. Esse fato ocorreu devido ao pequeno tamanho da falha, possibilitando um rápido retorno deambulatório. Por essa razão, também, as mensurações da perimetria da coxa não variaram entre as avaliações individuais de cada animal, pois não houve o desenvolvimento de atrofia. Mesmo o uso de imobilização com a bandagem de Robert Jones modificada durante os sete primeiros dias de pós-operatório não resultou em atrofia, pois essa bandagem aplicada em posição anatômica do membro, no padrão em estação, permite a deambulação imediata.

As medidas obtidas por meio da mensuração da perimetria da coxa neste trabalho não variaram entre as avaliações individuais de cada animal, demonstrando que não houve o desenvolvimento de atrofia, o que é condizente com os resultados do grau de claudicação, pois o rápido retorno deambulatório impede o aparecimento da atrofia. A atrofia muscular é uma mudança que ocorre nos músculos de animais adultos em resultado a condições de desuso, podendo ocorrer nos casos em que seja necessário instituir uma imobilização (Jackman e Kandarian, 2004). O uso de imobilização por meio da bandagem de Robert Jones modificada durante os sete primeiros dias de pós-operatório não resultou em atrofia, provavelmente por essa bandagem ser aplicada em posição anatômica do membro, no padrão em estação, permitindo a deambulação imediata.

O exame radiográfico aos 30 dias não demonstrou completa cicatrização em nenhum dos animais, corroborando os achados de Toal (1994), que descreve que nas fraturas com consolidação óssea secundária, em torno da quarta semana, o calo periosteal apresenta-se mais regular e opaco, sendo visibilizado como bainha óssea direcionando-se para unir a falha da fratura, e, somente após a quarta semana, a linha 
de fratura é gradualmente preenchida. Isso indica que, para um melhor aproveitamento desse exame, seria interessante uma avaliação por período mais prolongado.

Os animais I (SF) e III (FTCM) obtiveram imagem radiográfica mais compatível com a cicatrização e, coincidentemente, eram os animais mais agitados. Para Guyton e Hall (1997), o estímulo mecânico é necessário para estimular uma resposta óssea local, proporcionando seu crescimento e remodelamento, ou seja, sua maior atividade promoveu neovascularização mais precoce, colaborando para a resposta óssea local.

$\mathrm{O}$ animal V (FCTM + PRP) apresentou radiograficamente um calo ósseo mais proeminente. Porém, com relação ao preenchimento da falha, foi classificado abaixo dos animais I e III e acima dos demais. A cicatrização não ocorre sem a angiogênese, que é reconhecida como passo essencial na osteogênese, sendo que as células dos capilares possuem relação direta na formação óssea devido à sua proximidade com os osteoblastos e células osteoprogenitoras nos sítios de nova formação óssea (Pelissier et al., 2006). O sistema arterial medular possui papel fundamental no suprimento sanguíneo do calo ósseo (Sousa, 2003); logo, é possível inferir que, quanto mais proeminente o calo, melhor vascularizado ele está, possuindo maior angiongênese. Portanto, faz-se necessário investigar também a dimensão do calo, pois ele pode estar relacionado à neoangiogênese e osteogênese precoce, apesar de ainda não existir adequada mineralização.

Na análise biomecânica, a avaliação anterior ao procedimento, avaliação 0 (AV.0) foi o parâmetro de comparação individual para as demais avaliações. A AV.0 também foi comparada a valores previamente determinados por Barbosa et al. (2011) para caracterizar se o apoio era normal ou se havia transferência de peso. Os animais I, II e III demonstraram transferência na AV.0. O primeiro e o terceiro transferiram o peso dos membros pélvico e torácico direito para o lado contralateral; o segundo transferiu o peso do membro pélvico direito (mpd) e membro torácico esquerdo (mte) para o membro torácico direito (mtd). Como são animais provenientes do biotério, apesar de terem sido feitos exames radiográficos pregressos para garantir a inexistência de problemas ósseos anteriores, não é possível antever algum trauma em tecidos moles que justificasse a transferência de apoio.

As avaliações biomecânicas aos 10, 20 e 30 dias de cada animal estão descritas a seguir. O animal I, na avaliação 10 (AV.10) reduziu o apoio no membro pélvico esquerdo (mpe), mpd e mte, tranferindo para o mtd. Na avaliação 20 (AV.20), reduziu o peso do mpe e mte, transferindo uma pequena parcela para mpd e a maior parte para mtd, mantendo transferência semelhante na avaliação 30(AV.30). O cão II, na AV.10, diminuiu o apoio no mpd e mpe, invertendo a transferência para o mte. Em AV.20, reduziu a porcentagem de transferência do mpd e mpe para o mte, mas passou a retirar peso do mtd e passar para o mte. Em AV.30, reduziu ainda mais a porcentagem de transferência do mpe para o mte, passou a apoiar mais mpd que em AV.0, mas aumentou o desvio de mtd para mte.

O animal III, na AV.10, reduziu o apoio do mpe, mpd e tem, desviando para mtd. Na AV.20, manteve semelhante o desvio do mpe e mte para mtd, porém aumentou o apoio em mpd. Na AV.30, manteve a redução do apoio no mpe, aumentou a redução no mte, transferindo uma maior parcela para mpd e o restante para mtd. O cão IV (FVE), na AV.10, reduziu o peso do lado direito e tranferiu uma pequena fração para o mpe e o restante para o mte. Na AV.20, a transferência do lado esquerdo para o direito passou a ser dividida igualmente entre mpd e mtd. Na AV.30, essa tranferência foi reduzida pela metade. $\mathrm{O}$ animal $\mathrm{V}$, na $\mathrm{AV} .10$, reduziu o apoio no mpd e mte, desviando uma menor porcentagem para o mpe e a maior fração para o mtd. Na AV.30, já apresentava o apoio normal. O cão do grupo VI (FVE +PRP), na AV.10, diminuiu o apoio no mpd e mte e translocou para o mpe e mtd. Na AV.20, manteve essa distribuição, reduzindo pela metade essa transferência na avaliação seguinte.

Classificando a recuperação dos animais por meio da avaliação na plataforma de força em padrão ortostático, o cão $\mathrm{V}$ possuiu os melhores resultados, com um retorno à distribuição normal do peso em 21 dias. Os cães II e III ficaram em segundo lugar, pois aos 30 dias, aparentemente, precisariam de apenas mais uma avaliação para o retorno à normalidade, seguidos dos animais I, 
IV e VI, respectivamente. A partir desses resultados, seria de grande valia um aumento no número de avaliações desse teste para elucidar qual o tempo de retorno à distribuição normal do peso de cada animal, e se realmente há um retorno à distribuição normal ou ocorre uma modificação permanente na distribuição do peso e para onde ocorre a transferência.

Foram realizadas biópsias aos 15 e 30 dias, pois tanto as células-tronco que secretam uma variedade de citocinas pró e anti-inflamatórias e fatores de crescimento (Monteiro et al., 2010) como o PRP através da liberação de fatores de crescimento em altas concentrações (Floryan e Berghoff, 2004), auxiliam na neoangiogênese precoce, possuindo ação durante o processo inicial de cicatrização.

Com relação à avaliação histológica, observou-se que há uma relação inversa entre tecido de granulação (TG) e osso trabecular maduro (TBM). Quanto maior a quantidade de TG, menor a de osso, sendo que os animais $\mathrm{V}$ e VI foram os melhores exemplos, na proporção de 1,5:4,5 (Fig. 1A) e 4:1 (Fig. 1B), respectivamente, aos 30 dias, estando os animais dos demais grupos em posição intermediária. A consolidação óssea é um processo extremamente complexo que pode ser dividido em três estágios principais: fase inflamatória, reparo e remodelação (Junqueira e Carneiro, 2004). Na fase inflamatória, logo após a formação do hematoma da fratura, este é substituído por tecido de granulação, que será substituído posteriormente por fibrocartilagem, até constituir o osso trabecular maduro (Porter et al., 1997). Portanto essa relação entre TG e TBM corrobora a literatura. Aos 15 dias, os animais I, II e VI possuíram proporções semelhantes a 4:2 (Fig. 1C), e o cão V, a proporção de 3:0,5 (Fig. 1D), estando os demais em posição intermediária. Notou-se que, dos 15 para os 30 dias, os animais II e $\mathrm{V}$ aumentaram significativamente a quantidade de TBM, invertendo a relação TG:TBM (Fig. 1E e F). Já os demais mantiveram ou reduziram a quantidade de TBM. Esse fato pode estar relacionado ao melhor desempenho precoce, ou ao uso da FVE associada ao PRP.

Nenhum dos cortes mostrou mineralização. Isso pode indicar que o osso não está pronto para tal. A matriz óssea consiste em substâncias orgânicas, principalmente colágeno tipo I, sendo a menor parte composta por proteoglicanos e proteínas não colágenas. A porção inorgânica é constituída por sais de cálcio e fosfato na forma de cristais de hidroxiapatita (Brown e Kramers, 1996). A proteína mais importante no início do processo é o colágeno do tipo 1 . A síntese de colágeno depende de boa irrigação, e a mineralização depende da associação entre o colágeno e a hidroxiapatita. Pode-se deduzir que, em algum momento entre os 30 e os 45 dias, a relação adequada entre os fatores propicia a mineralização.

Não se observou uma relação linear entre a maturidade do tecido e o número de células computadas; tampouco uma relação linear entre a maturidade do tecido e o número de células marcadas pela vimentina. Os cães V e I foram os que obtiveram, respectivamente, maior e menor marcação do número de células pela vimentina (Fig. 1G e H). Notou-se uma redução da contagem de células dos 15 para os 30 dias em todos os animais, sendo a maior queda observada no cão II. O estágio do calo mole termina quando os fragmentos ósseos se tornam unidos por tecido fibroso ou cartilaginoso, o que ocorre em aproximadamente 2 a 3 semanas. Há grande aumento tanto na vascularidade quanto na celularidade, e a fibrocartilagem começa a substituir o tecido de granulação (Porter et al., 1997). Portanto a redução na contagem celular dos 15 para os 30 dias é condizente com a literatura, já que esse aumento ocorreria aproximadamente dos 15 aos 21 dias, reduzindo a seguir, e não sendo mais verificado aos 30 dias. A partir dos resultados obtidos no estudo piloto, observou-se a importância de algumas modificações para estudos futuros, como a necessidade de biópsias aos 15 e 45 dias para uma avaliação histológica mais eficiente. Para não precisar usar 60 cães, o que tornaria inviável a execução do estudo, optou-se pela biópsia aos 15 dias, com retirada de todo osso neoformado e novo tratamento, seguido das demais avaliações durante 45 dias, com nova biópsia nesse momento. Dessa forma, seria realizado um maior tempo de acompanhamento pós-cirúrgico, aproveitando melhor os resultados que cada método de avaliação pode fornecer. Ao analisar em conjunto as avaliações clínica, radiográfica, biomecânica e histológica, observou-se um destaque no animal $\mathrm{V}$, indicando, neste estudo, a possibilidade de ser o melhor tratamento para acelerar a cicatrização óssea. 

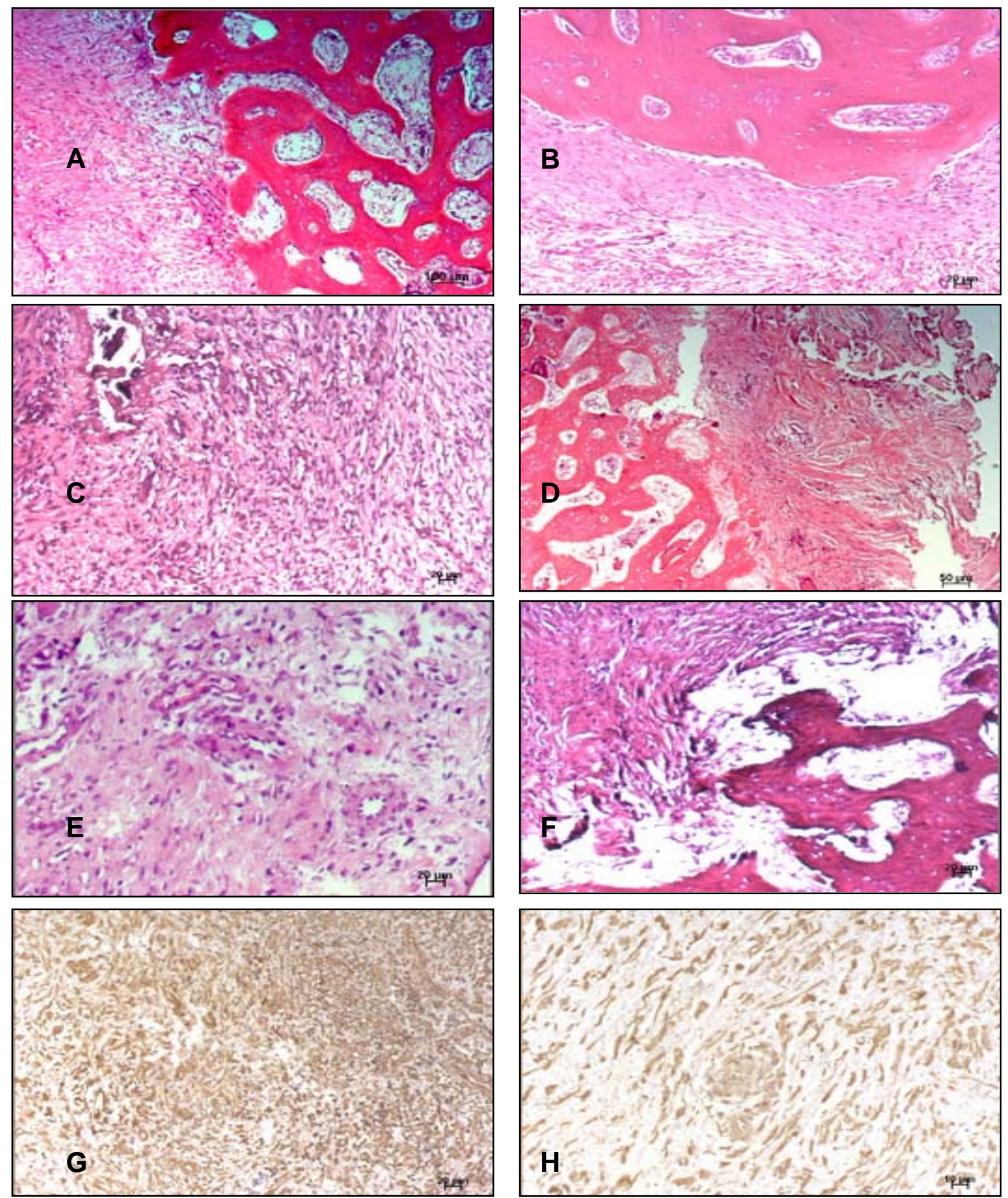

Figura 1. Imagens histológicas dos animais apresentados no estudo. A - Animal V demonstrando a relação inversa 1,5:4,5 tecido de granulação (TG) e osso trabecular maduro (TBM), aos 30 dias, na coloração HE, objetiva 5x; B - Animal VI demonstrando a relação inversa 4:1 de TG:TBM, 30 dias, HE, objetiva 10x; C - Animal I demonstrando a relação inversa 4:2 de TG:TBM, 15 dias, HE, objetiva 10x; D - Animal V demonstrando a relação inversa 3:0,5 de TG:TBM, 15 dias, HE, objetiva 10x; E e F - Animal II demonstrando o aumento significativo do TBM dos 15 (E) aos 30 dias (F), invertendo a relação TG:TBM, HE, objetiva 10x; G - Animal V demonstrando a maior marcação de células pela vimentina entre grupos, 30 dias, objetiva 10x; H - Animal I demonstrando a menor marcação de células pela vimentina entre grupos, 30 dias, objetiva 20x. 


\section{CONCLUSÃO}

O trabalho permitiu a padronização adequada de técnicas, possibilitando o teste da associação entre as Células-Tronco Mononucleares (CTMs) e o plasma rico em plaquetas (PRP), assim como seu uso isolado, no reparo de falhas ósseas corticais, em um estudo piloto. Demonstrou a possibilidade de a associação da fração total de Células-Tronco Mononucleares (FTCM) e o PRP ser o melhor tratamento para acelerar a cicatrização óssea, o que precisa ser confirmado em um estudo futuro com uma amostra adequada.

\section{AGRADECIMENTO}

Ao CNPq pelo apoio, processo: 300885/2008-3. Ao Setor de Radiologia da UFSM pelo auxílio nos exames radiográficos.

\section{REFERÊNCIAS}

BARBOSA, A.L.T.; DEL CARLO, R.J.; GOMES, H.C. et al. Plasma rico em plaquetas para reparação de falhas ósseas em cães. Cienc. Rural, v.38, p.1335-1340, 2008.

BARBOSA, A.L.T.; SCHOSSLER, J.E.W.; BOLLI, C.M. et al. Padronização e teste da plataforma de força em padrão ortostático em cães. Arq. Bras. Med. Vet. Zootec., v.63, p.559566, 2011.

BOUXSEIN, M.L.; TUREK, T.J.; BLAKE, C.A. et al. Recombinant human bone morphogenetic protein-2 accelerates healing in a rabbit ulnar osteotomy model. J. Bone Joint Surg. Am., v.83, p.1219-1230, 2001.

BOYUM, A. Separation of leukocytes from blood and bone marrow. Scand. J. Clin. Lab. Invest., v.21, p.77-79, 1968.

BRANDÃO, G.H.F. Estudo comparativo entre a eficácia clínica de enxertos ósseos (autógenos, alógenos, aloplásticos) com ou sem utilização de plasma rico em plaquetas. 2005. Disponível em: <http://www.medcenter.com>. Acessado em: 12 jun. 2005.

BROWN, S.G.; KRAMERS, P.C. Consolidação óssea indireta (secundária). In: BOJHAB, M.J. Mecanismos da moléstia na cirurgia dos pequenos animais. 2.ed. São Paulo: Manole, 1996. Cap. 97, p.783-790.
BUCHOLZ, R.W. Nonallograft osteocondutive boné graft substitutes. Clin. Orthop. Relat. Res., v.395, p.44-52, 2002.

FLORYAN, K.M.; BERGHOFF, W.J. Intraoperative use of autologous PRP and PRP for orthopedic surgery patients. AORN Journal, v.80, p.668-674, 2004.

GENGOZIAN, N. Identification and isolation of hematopoietic progenitors. In: FELDMAN, B.F. et al. Schalm's veterinary hematology. Philadelphia: Williams \& Wilkins, 2000. Cap.16, p.91-96.

GUYTON, A.C.; HALL, J.E. Tratado de fisiologia médica. 9.ed. Rio de Janeiro: Guanabara Koogan, 1997, 1014p.

JACKMAN, R.W.; KANDARIAN, S.C. The molecular basis of skeletal muscle atrophy. Am. J. Physiol. Cell Physiol., v.287, p.834-843, 2004.

JUNQUEIRA, L.C.; CARNEIRO, J. Histologia básica. 10.ed. Rio de Janeiro: Guanabara Koogan, 2004. p.136-148.

KAIGLER, D.; MOONEY, D. Tissue engineering's impact of dentistry. J. Dent. Educ., v.65, p.456-462, 2001.

LIEBERMAN, J.R.; DALUISKI, A.; EINHORN, T.A. The hole of Growth Factors in the repair bone. $J$. Bone Joint Surg. Am., v.84, p.1032-1042, 2002.

MARX, R.E. Platelet-rich plasma: evidence to support its use. J. Oral Maxillof. Surg., v.62, p.489-496, 2004.

MONTEIRO, B.S.; NETO, M.N.A.; DEL CARLO, R.J. Células-tronco mesenquimais. Cienc. Rural, v.40, p.238-245, 2010.

OLSSON, D.C. Transplante de células-tronco com a fração total de células mononucleares autógenas da medula óssea na lesão iatrogênica aguda de tendão calcâneo de cães. 2009. $106 f$. Tese (Doutorado em Medicina Veterinária) Faculdade de Medicina Veterinária, Universidade Federal de Santa Maria, Santa Maria, RS.

PELISSIER, P.H.; MASQUELET, A.C.; BAREILLE, R. et al. Induced membranes secrete growth factors including vascular and osteoinductive factors and cold stimulate bone regeneration. J. Orthop. Res., v.22, p.73-79, 2006. 
PORTER, G.A.; GURLEY, M.; ROTH, S.I. Bone. In: STERNBERGER, S.S. Histology for Pathologists. 2.ed. Philadelphia: LippincottRaven, 1997. cap. 5, p.85-105.

SMITH, J.J.; ROSS, M.W.; SMITH, R.K.W. Anabolic effects of acellular bone marrow, platelet rich plasma, and serum on equine suspensory ligament fibroblasts in vitro. Vet. Comp. Orthop. Traumatol., v.19, p.43-47, 2006.

SOUSA, V.L. Efeitos do ultra som de baixa intensidade sobre a consolidação óssea em fratura de ossos longos (rádio e ulna, tíbia e fíbula) em cães (Canis familiaris). 2003. 127f. Dissertação (Mestrado em Medicina Veterinária - Faculdade de Medicina Veterinária e Zootecnia, Universidade de São Paulo, São Paulo, SP.

STREM, B.M.; HICOK, K.C.; ZHU, M. et al. Multipotential differentiation of adipose tissuederived stem cells. Keio J. Med., v.54, p.132, 2005.
SUTER, S.E.; GOUTHRO, T.A.; MCSWEENEYET, P.A. et al. Isolation and characterization of pediatric canine bone marrow CD34+. Vet. Immunol. Immunopathol., v.101, p.31-47, 2004.

TREICHEL, T.L.E. Transplante de fração total de células mononucleares ou fração vascular estromal associada à membrana celulósica em feridas cutâneas experimentais de coelhos. Braz. J. Vet. Res. Anim. Sci., v.48, p.62-72, 2011.

TOAL, R.L. Fracture healing and complications. In: THRALL, D.E. Textbook of veterinary diagnostic radiology. 2.ed. Philadephia: Saunders, 1994. p.105-123.

TUDURY, E.A.; RAISER, A.G. Redução de fraturas distais do fêmur de cães empregando dois pinos de Steinmann em substituição aos de Rush. Rev. Cent. Cienc. Rurais, v.15, p.141-155, 1985. 